\title{
Message from the new editors of Arquivos de Neuro-Psiquiatria
}

Mensagem dos novos editores de Arquivos de Neuro-Psiquiatria

Hélio A. Ghizoni Teive ${ }^{1,2}$, Paulo Caramellii,4

${ }^{1}$ Universidade Federal do

Paraná, Faculdade de Medicina, Departamento de Clínica Médica, Curitiba PR, Brasil;

¿Universidade Federal do Paraná, Hospital de Clínicas, Serviço de Neurologia, Curitiba PR, Brasil; ${ }^{3}$ Universidade Federal de Minas Gerais, Faculdade de Medicina, Departamento de Clínica Médica, Belo Horizonte MG, Brasil; «Universidade Federal de Minas Gerais, Hospital das Clínicas, Serviço de Neurologia, Belo Horizonte MG, Brasil.

\section{Correspondence:}

Editors; Rua Vergueiro, 1353 / conj. 1404; 04101-000 São Paulo SP, Brasil; E-mail: revista.arquivos@ abneuro.org

Conflict of Interest:

There is no conflict of interest to declare.

Received 04 December 2017 Accepted 11 December 2017.

\section{(cc) BY}

I $\mathrm{t}$ is with great honor and pleasure that we assume the position of editors-in-chief of Arquivos de Neuro-Psiquiatria. Arquivos moves into its $75^{\text {th }}$ year of existence as one of the leading scientific journals in the areas of Clinical Neurology and Neurosciences in Latin America. This international recognition is the result of the outstanding work done by the journal's previous editors, Professors Oswaldo Lange, Antonio Spina-França Netto and, for the last seven years, José Antonio Livramento and Luis dos Ramos Machado. We are very grateful for their work and, in particular, for the generous support from Professors Livramento and Machado over the past year, in sharing with us their expertise and experience as the journal's editors. We also thank the past members of the editorial board. The efforts of all these colleagues have increased our responsibility for leading the editorial board of Arquivos in the upcoming years.

As an initial step in our editorship period, we have proposed some modifications to the editorial board, either in its form or its composition. The national and international boards have been merged, and now include 50 colleagues from Brazil and from other 10 countries ( from South America, North America and Europe), representing the main areas of Neurology and related disciplines. Several colleagues have been invited to join the editorial board, as well as some previous members having agreed to continue to serve on the journal's board. Area supervisors and associate editors have also been combined into an associate editors panel and assigned to 21 research fields. Investigators from Brazil, Canada, United Kingdom and USA have accepted our invitation and will assume a capital role in the editorial process. We greatly appreciate the commitment of all these colleagues in joining the editorial board of Arquivos.

We have also modified the journal cover. A new set of colors was adopted and each issue will display a figure selected from one of the published manuscripts. We thank the staff of Caboverde for their technical support in the development of the new design.

Our goal is to further increase the journal's international visibility and scientific quality. The fact that Arquivos is a free-of-charge and open-access journal is a major asset in the current worldwide scientific context, which contributes to the attraction of a growing number of high-quality manuscripts from several different countries.

Finally, we would like to thank the Brazilian Academy of Neurology, the publisher of Arquivos de Neuro-Psiquiatria, for the financial support of the journal and the personal credit granted to us as new editors.

Hélio Afonso Ghizoni Teive and Paulo Caramelli Editors-in-chief, Arquivos de Neuro-Psiquiatria 